\title{
Controllable Preparation of a Three-Dimensional Porous Lead Dioxide Electrode with an Oxygen Bubble Template and Its Electrocatalytic Performance
}

\author{
Qi Hu, Qiang Yu*, Zhen Chen, Wei Zhu, Yuanyuan Liu, Zhaoyi Zheng, Lai Gui, Yuzhu Song \\ Faculty of Science, Kunming University of Science and Technology, Kunming 650093, China \\ "E-mail: yuqiang0015@163.com
}

doi: $10.20964 / 2021.01 .58$

Received: 3 August 2020 / Accepted: 10 November 2020 / Published: 30 November 2020

\begin{abstract}
Three-dimensional porous $\mathrm{PbO}_{2}\left(3 \mathrm{D}-\mathrm{PbO}_{2}\right)$ electrode was prepared by anodic oxidation deposition method, using an oxygen bubble template. To prepare $3 \mathrm{D}-\mathrm{PbO}_{2}$ electrode controllably , the influence of current density, $\mathrm{Pb}^{2+}$ ion concentration, and $\mathrm{pH}$ value on the structure and performance of $\mathrm{PbO}_{2}$ electrode was studied. The results show that the current density determined the appearance of oxygen bubbles. The nucleation and growth of the oxygen bubbles were controlled by $\mathrm{Pb}^{2+}$ concentration and the $\mathrm{pH}$ value, respectively. The effect of the process conditions on the performance of electrode materials was obtained by comparing the electrocatalytic activities of the electrodes. The morphology and phase composition of the different anode materials were analyzed, and electrocatalytic activities were investigated by cyclic voltammetry (CV) and electrochemical impedance spectroscopy (EIS). The CV curve shows that the total voltammetric charge $\left(\mathrm{q}_{\mathrm{T}}{ }^{*}\right)$ of the $3 \mathrm{D}-\mathrm{PbO}_{2}$ electrode was 70 times larger than that of the flat- $\mathrm{PbO}_{2}$ electrode. In addition, during the evolution of oxygen, the $3 \mathrm{D}-\mathrm{PbO}_{2}$ electrode had a higher exchange current density $\left(j^{0}\right)$, lower apparent activation energy $\left(E_{a}\right)$ and lower charge transfer resistance $\left(\mathrm{R}_{\mathrm{ct}}\right)$ than the flat- $\mathrm{PbO}_{2}$ electrode.
\end{abstract}

Keywords: oxygen bubble template method; controllable preparation; lead dioxide; anode materials; electrocatalytic performance

\section{FULL TEXT}

(C) 2021 The Authors. Published by ESG (www.electrochemsci.org). This article is an open access article distributed under the terms and conditions of the Creative Commons Attribution license (http://creativecommons.org/licenses/by/4.0/). 